\title{
Correction to: Artificial intelligence with robotics for advanced manufacturing industry using robot-assisted mixed-integer programming model
}

\author{
Hong Xiao ${ }^{1} \cdot$ BalaAnand Muthu ${ }^{2}$ Seifedine Nimer Kadry ${ }^{3}$ \\ ๑) Springer-Verlag GmbH Germany, part of Springer Nature 2020 \\ Correction to: Intelligent Service Robotics \\ https://doi.org/10.1007/s11370-020-00326-7
}

The original version of this article contains a missing space between the name and middle name of the third author. The correct is: Seifedine Nimer Kadry.

This erratum corrects the mistake and the original article is updated.

Publisher's Note Springer Nature remains neutral with regard to jurisdictional claims in published maps and institutional affiliations.

The original article can be found online at https://doi.org/10.1007/ s11370-020-00326-7.

Hong Xiao

Xiaohong198017@163.com

BalaAnand Muthu

balavdy@gmail.com

Seifedine Nimer Kadry

s.kadry@bau.edu.lb

1 School of Finance and Economics, Anhui Science and Technology University, Bengbu 233100, AnHui, China

2 V.R.S. College of Engineering and Technology, Villupuram, India

3 Beirut Arab University, Lebnon, Lebanon 